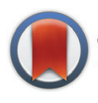

CrossMark $\leftarrow$ click for updates

Cite this: Dalton Trans., 2016, 45 8984

\title{
Origin of a counterintuitive yellow light-emitting electrochemical cell based on a blue-emitting heteroleptic copper(ı) complex†
}

\author{
Michael D. Weber, ${ }^{a}$ Claudio Garino, ${ }^{\mathrm{b}}$ Giorgio Volpi, ${ }^{\mathrm{b}}$ Enrico Casamassa, \\ Marco Milanesio, ${ }^{\mathrm{C}}$ Claudia Barolo*b and Rubén D. Costa*a
}

\begin{abstract}
This work provides the synthesis, structural characterization, electrochemical and photophysical features, as well as the application in light-emitting electrochemical cells (LECs) of a novel heteroleptic copper(I) complex - [Cu(impy)(POP)][PF 6 , where impy is 3-(2-methoxyphenyl)-1-(pyridine-2-yl)imidazo[1,5-a]pyridine and POP is bis $\{2$-(diphenylphosphanyl)phenyl\}ether. This compound shows blue photoluminescence $(\mathrm{PL}, \lambda=450 \mathrm{~nm})$ in solution and solid-state and excellent redox stability. Despite these excellent features, the electroluminescence (EL) response is located at $\sim 550 \mathrm{~nm}$. Although the EL spectrum of LECs is typically red-shifted compared to the PL of the electroluminescent material, a shift of ca. $100 \mathrm{~nm}$ represents the largest one reported in LECs. To date, the large shift phenomena have been attributed to (i) a change in the nature of the lowest emitting state due to a concentration effect of the films, (ii) a reversible substitution of the ligands due to the weak coordination to the $\mathrm{Cu}(\mathrm{I})$, and (iii) a change in the distribution of the excited states due to polarization effects. After having discarded these along with others like the irreversible degradation of the emitter during device fabrication and/or under operation conditions, driving conditions, active layer composition, and changes in the excited states under different external electrical stimuli, we attribute the origin of this unexpected shift to a lack of a thermally activated delayed fluorescence (TADF) process due to the solely ligand-centered character of the excited states. As such, the lack of a charge transfer character in the excited states leads to a blue-fluorescence and yellowphosphorescence photo- and electro-responses, respectively. This corroborates recent studies focused on the design of TADF for heteroleptic copper(I) complexes. Overall, this work is a clear insight into the design of new copper(I) complexes towards the preparation of blue LECs, which are still unexplored.
\end{abstract} Received 11th March 2016, DOI: $10.1039 / \mathrm{c} 6 \mathrm{dt} 00970 \mathrm{k}$

www.rsc.org/dalton

\section{Introduction}

Copper(I) complexes are considered as a rising electroluminescent material for organic light-emitting diodes (OLEDs) ${ }^{1-8}$ and light-emitting electrochemical cells (LECs). ${ }^{9-16}$ This is attributed to their simple and low-cost synthesis, as well as the ease of chemical modifications for fine-tuning their photoluminescence and electrochemical features. In addition, they

\footnotetext{
${ }^{a}$ Department of Physical Chemistry 1, University of Erlangen-Nürnberg, Egerlandstr. 3, 91058 Erlangen, Germany. E-mail: ruben.costa@fau.de

${ }^{b}$ Department of Chemistry and NIS Interdepartmental Centre, University of Torino, Via Pietro Giuria 7, 10125 Torino, Italy. E-mail: claudia.barolo@unito.it ${ }^{c}$ Dipartimento di Scienze e Innovazione and CrisDi Interdepartmental Center for Crystallography, Università del Piemonte Orientale Tecnologica, Viale T. Michel 11, 15121 Alessandria, Italy

$\dagger$ Electronic supplementary information (ESI) available: X-ray characterization, computational results, and device performance. CCDC 1452806. For ESI and crystallographic data in CIF or other electronic format see DOI: 10.1039/ c6dt00970k
}

typically show a two-excited state radiative mechanism that involves the thermal repopulation of the emitting singlet excited state from the lowest-lying triplet state, i.e., thermally activated delayed fluorescence (TADF). ${ }^{5,7,8,17-19}$ Thus, the implementation of copper(I) complexes in lighting devices might provide an efficient way to reform the emitting singlets, i.e., singlet harvesting, increasing the spin statistics and the device efficiency. ${ }^{1-8,19}$

Encouraged by the aforementioned, heteroleptic copper(I) complexes based on diimine $\left(\mathrm{N}^{\wedge} \mathrm{N}\right)$ and diphosphine $\left(\mathrm{P}^{\wedge} \mathrm{P}\right)$ ligands, i.e., $\left[\mathrm{Cu}\left(\mathrm{N}^{\wedge} \mathrm{N}\right)\left(\mathrm{P}^{\wedge} \mathrm{P}\right)\right]^{+}$, have been recently revisited by several groups. ${ }^{2,9,12,14,17,18,20,21}$ They have established several simple guidelines for enhancing both the synthesis proto$\mathrm{col}^{20,21}$ and the ligand design ${ }^{2,17,18}$ to take full advantage of the photoluminescence and electrochemical features of these materials. More striking, these guidelines have also proven to be useful for enhancing their electroluminescence features. Here, the LEC configuration, which is a single-component and single-layer device, has allowed a straightforward establish- 
ment of material design/device performance relationships. ${ }^{9,10,15}$ As prime examples in $\left[\mathrm{Cu}\left(\mathrm{N}^{\wedge} \mathrm{N}\right)\left(\mathrm{P}^{\wedge} \mathrm{P}\right)\right]^{+}$LECs, the efficiency and the stability have been enhanced by designing $\mathrm{N}^{\wedge} \mathrm{N}$ ligands with substituents strategically attached to shield the coordination sphere and/or increasing the planarity of the ligands. ${ }^{9,13-16,22-24}$

These recent achievements pinpoint the great potential of copper(I) complexes to replace complexes based on the much more rare and expensive iridium(III) in the near future. In this context, the quest for blue LECs based on copper(I) complexes is at the forefront of the field. As a matter of fact, despite huge efforts, stable blue LECs based on iridium(III) complexes are still missing. ${ }^{9,10,25-27}$ This is related to their intrinsic degradation via the metal-centered (MC) states, which are not present in copper(I) complexes. ${ }^{28}$ As such, much more stable blue devices are expected by using the latter. However, the state-of-the-art $\left[\mathrm{Cu}\left(\mathrm{N}^{\wedge} \mathrm{N}\right)\left(\mathrm{P}^{\wedge} \mathrm{P}\right)\right]^{+}$LEC only involves a few examples of yellow and green emitting devices with brightness values of $10-50 \mathrm{~cd} \mathrm{~m}^{-2}$ and stabilities of a few hours. ${ }^{9,14,15,22-24}$ This contrasts with the number of $\left[\mathrm{Cu}\left(\mathrm{N}^{\wedge} \mathrm{N}\right)\right.$ $\left.\left(\mathrm{P}^{\wedge} \mathrm{P}\right)\right]^{+}$covering the whole visible range. ${ }^{2,7-9,19,28}$

In an attempt to develop the first blue LEC based on $\left[\mathrm{Cu}\left(\mathrm{N}^{\wedge} \mathrm{N}\right)\left(\mathrm{P}^{\wedge} \mathrm{P}\right)\right]^{+}$, while providing a new member to this wellknown family, we explored the synthesis and the application of the $[\mathrm{Cu}(\mathrm{impy})(\mathrm{POP})]\left[\mathrm{PF}_{6}\right]$ (1) complex, where impy is 3-(2-methoxyphenyl)-1-(pyridine-2-yl)imidazo[1,5-a]pyridine and POP is bis $\{2$-(diphenylphosphanyl)phenyl $\}$ ether - Fig. 1. Here, the selection of the ancillary impy ligand was based on its simple one-pot synthesis and its absorption features in the ultraviolet region that might provide emission responses in the deep-blue region of the visible spectrum, ${ }^{29-31}$ while the POP was selected as its bite angle stabilizes the tetrahedral coordination sphere in the excited state and avoids the formation of di-nuclear species. $^{20,21}$ Although 1 shows a deep-blue emission $(\lambda=$ $450 \mathrm{~nm}$ ) in solution, thin films, and crystalline powder, the device shows a yellow electroluminescence centered at $\sim 550 \mathrm{~nm}$. This cannot be rationalized by standard arguments, such as the degradation of the emitter during device fabrication and/or under operation conditions, driving conditions, active layer composition, and changes in the excited states due

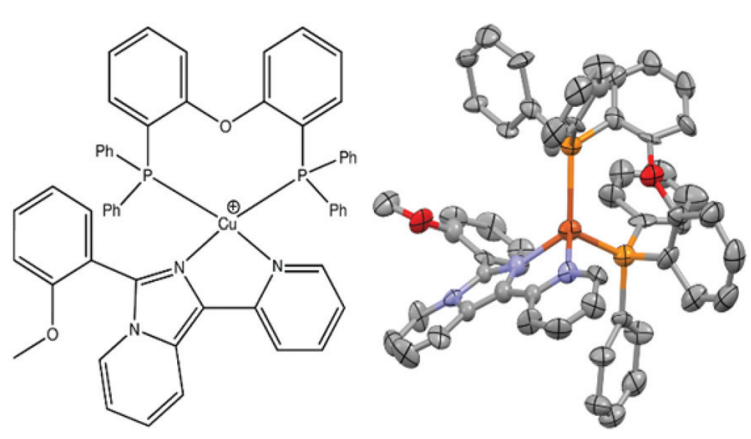

Fig. 1 Chemical (left) and molecular structures with thermal ellipsoid depicted at $25 \%$ probability from X-ray data (right) of [Cu(impy) (POP)] $\left[\mathrm{PF}_{6}\right]$ (1). $\mathrm{H}$ atoms have been omitted for clarity purposes. to polarization effects. Herein, we demonstrate that this counterintuitive shift is related to the lack of TADF that leads to a blue photoluminescence from the lowest singlet excited state (S1) and a yellow electroluminescence from the lowest-lying triplet state (T1) without having the chance of TADF even when high temperatures are externally applied to the device.

\section{Results and discussion}

The synthesis of the new $\mathrm{N}^{\wedge} \mathrm{N}$ ligand impy was performed with a one-pot microwave assisted synthetic protocol with a very good yield - see the Experimental section. ${ }^{51}$ Complex 1 was prepared in an excellent yield by a quick reaction at room temperature of $\left[\mathrm{Cu}\left(\mathrm{CH}_{3} \mathrm{CN}\right)_{4}\right]\left[\mathrm{PF}_{6}\right]$ with one equivalent of the POP ligand followed, after a period of time, by one equivalent of the impy ligand in $\mathrm{CH}_{2} \mathrm{Cl}_{2}$ solution. ${ }^{20,21}$

${ }^{1} \mathrm{H}$ and ${ }^{13} \mathrm{C}$ NMR characterization together with X-ray data confirm the formation of the heteroleptic complex 1 with no evidence of either the presence of homoleptic species or free ligands. Furthermore, crystals of $\mathbf{1}$ (Fig. 1) were also isolated by slow crystallization and used for photophysical characterization - hereafter it is referred to as crystalline powder. In detail, 1 crystallizes in the $P 2_{1} / c$ space group - Tables $\mathrm{S} 1-\mathrm{S} 4 . \dagger$ The $\mathrm{Cu}$ atom shows a non-planar pseudo-tetrahedral coordination with the two $\mathrm{P}$ atoms of the POP moiety $(\mathrm{P}-\mathrm{Cu}-\mathrm{P}=$ $110.6^{\circ}$ ) and the two $\mathrm{N}$ atoms of the impy moiety (Fig. 1). However, the steric constraints of this rigid impy moiety impose bonding angles of $\mathrm{Cu}$ with $\mathrm{N}$ and $\mathrm{P}$ atoms different from $109^{\circ}$ (values ranging from $80^{\circ}$ to $120^{\circ}$ ). The coordination of POP generates an 8-member ring formed by the central $\mathrm{Cu}$ atom, the two $\mathrm{P}$ atoms, the bridging $\mathrm{O}$ atom and four $\mathrm{C}$ atoms of the two phenyl moieties. The $\mathrm{Cu}-\mathrm{P}$ distances are 2.27 and $2.28 \AA$ A. The oxygen bridge between the two phenyls shows $\mathrm{C}-\mathrm{O}$ distances of 1.37 and $1.38 \AA$, values typical of an aromatic bond, suggesting a delocalization of the electrons across the bridge. The DFT-optimized molecular geometry of the isolated complex is similar to that from the crystal structure, indicating a rather high rigidity of the cluster. The packing is arranged in rows of $\mathrm{PF}_{6}{ }^{-}$moieties along $a$ and $b$ crystal axes, surrounded by the positively-charged complexes. This arrangement might explain the preferred growth in two directions to form extended laminae, whilst in the third direction the growth is probably unfavoured because no regular rows of positive and negative ions are observed.

The absorption and emission features of 1 were investigated in ACN, thin film, and crystalline powder (Fig. 2, S1, and S2 $\dagger$ ). The absorption spectrum is characterized by two intense bands centered at around 290 and $375 \mathrm{~nm}$ (Fig. S1†).

According to the theoretical studies based on DFT and TD-DFT approaches, the high-energy band in the absorption spectrum has a mixed character, being composed of a series of electronic transitions with metal-to-ligand charge transfer (MLCT) or ligand-to-ligand charge transfer (LLCT) characters. Conversely the lowest-energy band has mainly a ligand-centered (LC) character - Table S5 and Fig. S2. $\dagger$ The photoluminescence 


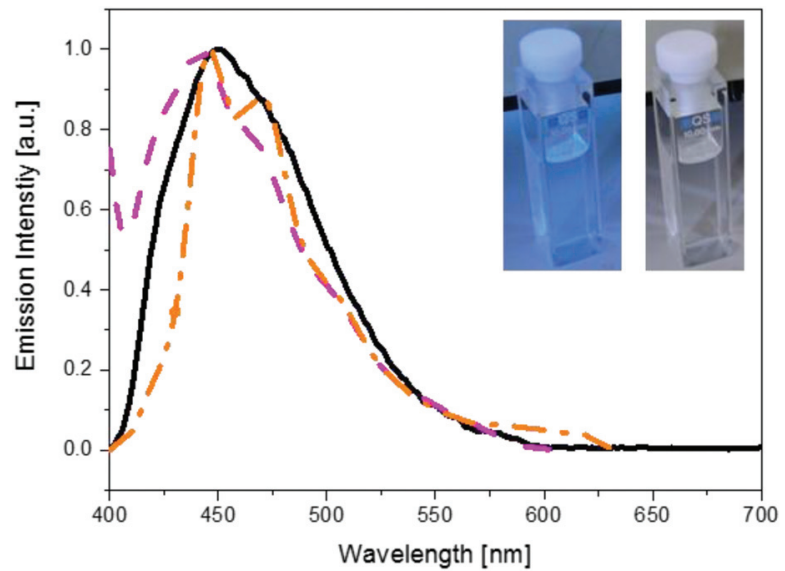

Fig. 2 Emission spectra of 1 in ACN solution (solid), crystalline powder (dashed), and spin-coated films (dash-dotted). Inset: pictures of the solution under UV irradiation (left) and room light (right).

(PL) spectrum in solution consists of an intense structured band centered at $\sim 450 \mathrm{~nm}$ and flanked by two shoulders at 425 and $475 \mathrm{~nm}$. The latter relates to photoluminescence quantum yields $\left(\phi_{\mathrm{em}}\right)$ and monoexponential excited state lifetime $(\tau)$ values of around $36 \%$ and $7.93 \mathrm{~ns}$, respectively. The same PL spectrum was noted in films and crystalline powder - Fig. 2 . Importantly, $\mathbf{1}$ features a sound stability in solution and thin films over several hours, suggesting that no degradation occurs during device fabrication (Fig. S1†).

Finally, we elucidated the electrochemical features by using cyclic (CV) and square wave (SQ) voltammetry - Fig. 3, in combination with computational methods - see the Experimental section. In detail, $\mathbf{1}$ shows three quasi-reversible oxidation waves at $+1.02,+1.28$, and $+1.51 \mathrm{~V}$, as well as a quasi-reversible reduction wave at $-2.32 \mathrm{~V}$. As a complement, the electronic structure of the ground state (GS) of $\mathbf{1}$ was optimized via DFT Tables S5 and S6 and Fig. S3 and S4. $\dagger$ Contrary to what is typically noted for $\left[\mathrm{Cu}\left(\mathrm{P}^{\wedge} \mathrm{P}\right)\left(\mathrm{N}^{\wedge} \mathrm{N}\right)\right]^{+}, 2,9,11,12,14,17,18,20,21,28$ the frontier molecular orbitals of $\mathbf{1}$ in the GS, i.e. HOMO (highest-occupied molecular orbital) and LUMO (lowest-unoccupied molecular orbital), are both located at the impy ligand - Fig. 3 and S4. $\dagger$ As such, both redox processes might occur at this ancillary ligand.

Impelled by the high blue-emission and the reversible redox features of $\mathbf{1}$, we turned to fabricate LECs with an active layer of $c a .90 \mathrm{~nm}$. The layer was spin-coated onto an indium tin oxide (ITO) electrode that was previously coated with a $90 \mathrm{~nm}$ thick layer of poly(3,4-ethylenedioxythiophene):polystyrene sulfonate (PEDOT:PSS). To finalize the devices, aluminium was evaporated as a top cathode - see the Experimental section for more details.

As expected by the reversible redox features of $\mathbf{1}$, the luminescence-current-voltage-sweeps (LIVs) under forward and reverse conditions show stable current density and luminance profiles, achieving maximum luminance values of $\sim 10 \mathrm{~cd} \mathrm{~m}^{-2}$ and efficacy values of $0.07 \mathrm{~cd} \mathrm{~A}^{-1}$ under forward conditions - Fig. 4. However, the electroluminescence (EL) spectrum significantly contrasts with the blue-emission noted for PL. Indeed, the EL
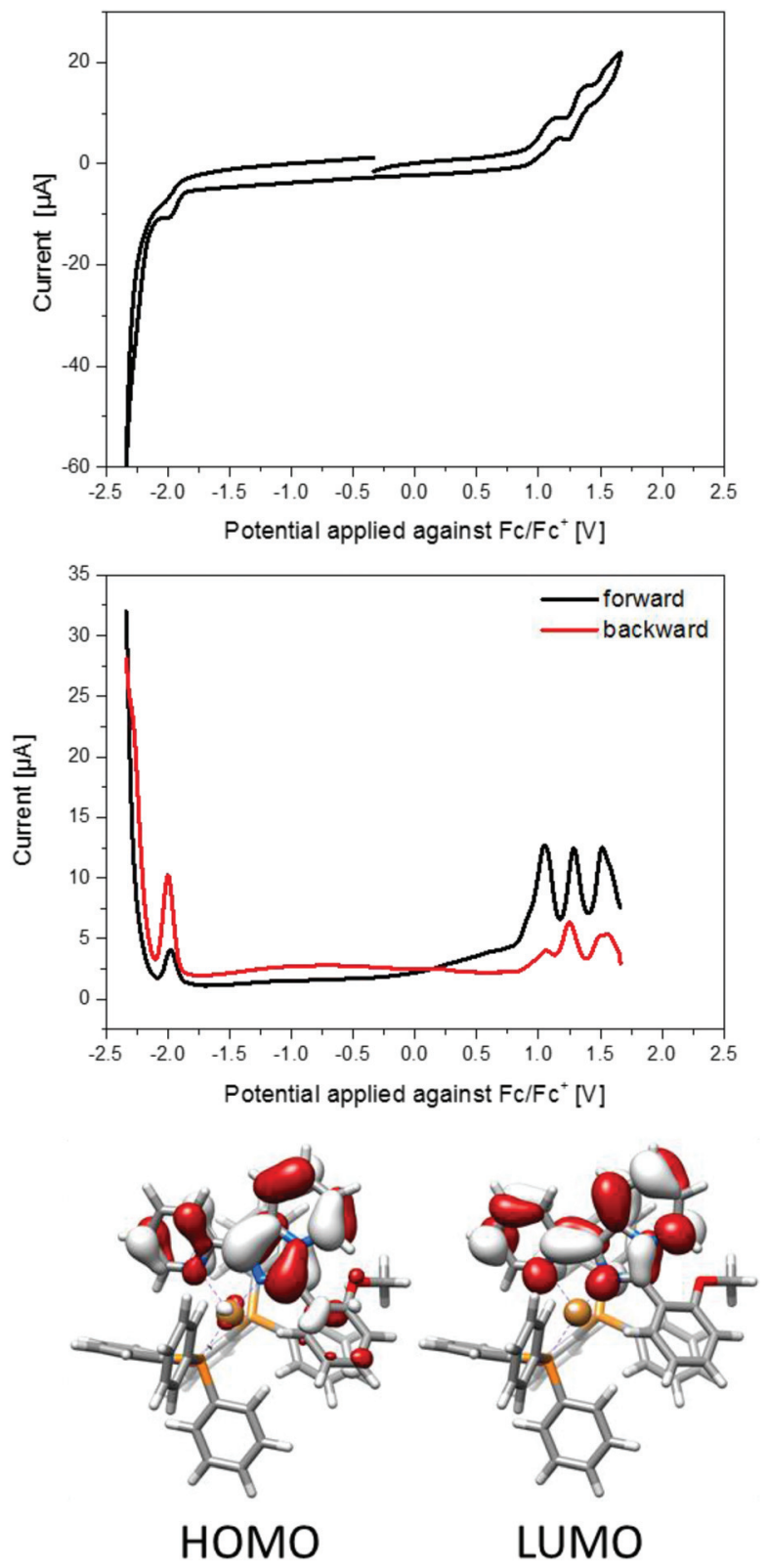

Fig. 3 Cyclic (top) and square wave (central) voltammograms of 1 in ACN solution. HOMO and LUMO topologies of 1 in GS (bottom).

consists of a structured band centred at $\sim 550 \mathrm{~nm}$ along with two shoulders at $\sim 510$ and $\sim 600 \mathrm{~nm}$ that corresponds to $x / y$ colour coordinates of $0.34 / 0.40$, that is, a yellow emitting device. These emission characteristics hold during LIV assays independently of the number of applied cycles as shown in Fig. 4.

This indicates that the yellow EL might be seen as an intrinsic electroluminescent feature of $\mathbf{1}$ and not due to the formation of other species under device operation conditions. To further corroborate this notion, two experiments were performed. On the one hand, static electrochemical impedance spectroscopy (EIS) characterization at different applied voltages was carried out in a fresh device and after applying 5 cycles of LIVs - see the Experimental section. The EIS analysis 

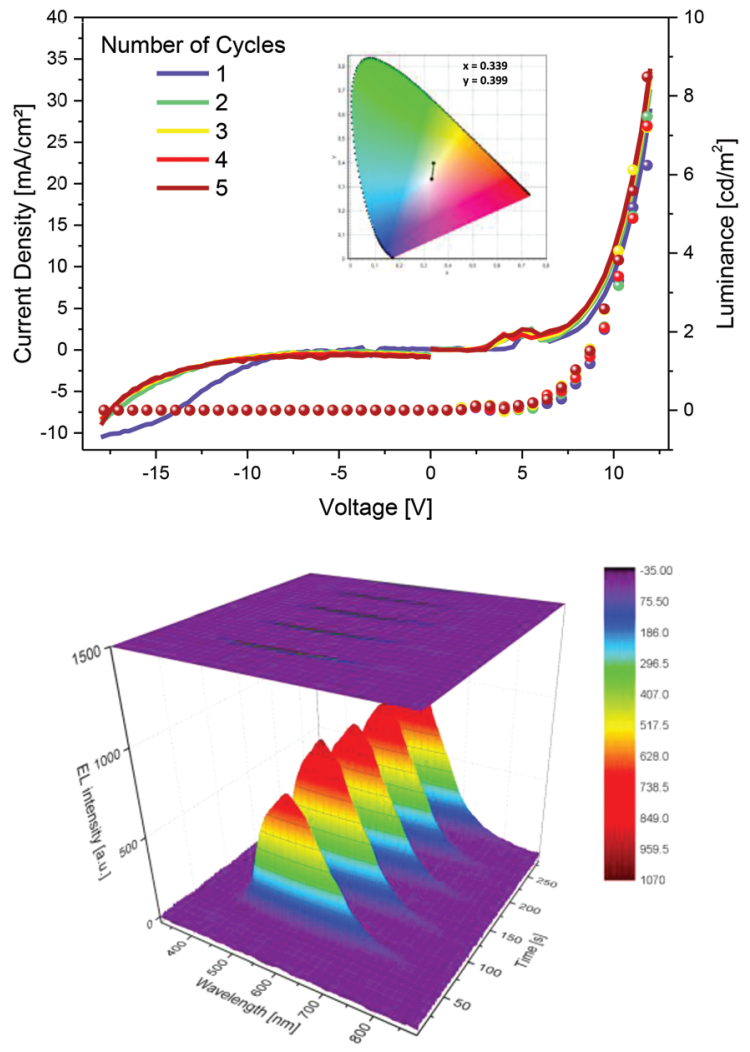

Fig. 4 (Top) Five repetitive LIVs (current density in solid lines and luminance in full symbols) of a device with 1 upon a voltage scan regime from -18 to $+12 \mathrm{~V}$. Inset: color coordinate diagram with the $x / y$ coordinates of the EL response. (Bottom) 3D plot of the EL spectra recorded during the LIV assays, highlighting no change in the EL response.

was conducted based on a single resistor/capacitor equivalent circuit model that relates to the dynamics ascribed either to the formation of the electrical double layers at the electrode interface until charge injection takes over or to the reduction of the $\mathrm{p}-\mathrm{i}-\mathrm{n}$ region at applied voltages lower and higher than the band gap of the compound, i.e., $c a .4 \mathrm{~V}$ as shown in Fig. $55, \dagger$ respectively. ${ }^{52,53}$ Since the resistance profile is unchanged after testing the device, we can postulate that the device mechanism is not altered, pointing to a lack of degradation of 1. On the other hand, the EL response over time was investigated by driving the devices at different average pulsed currents of 1, 2.5, 5, and $7.5 \mathrm{~mA}$ - Fig. 5 and S6-8, $\dagger$ as well as Table 1. The LEC behaviour is highlighted by the changes in the average voltage and luminance profiles. The former is initially high due to the random distribution of the mobile anions, which under the electrical conditioning redistribute towards the electrodes. This assists the charge injection that reduces the applied average voltage, which remains constant over time, suggesting no degradation of $\mathbf{1}$ under operation conditions - vide supra. An almost instantaneous luminance quickly increases to a maximum value of $\sim 15 \mathrm{~cd} \mathrm{~m}^{-2}$. This is followed by luminance decay due to the reduction of the $\mathrm{p}-\mathrm{i}-\mathrm{n}$ region, showing stability values of up to several hours depend-

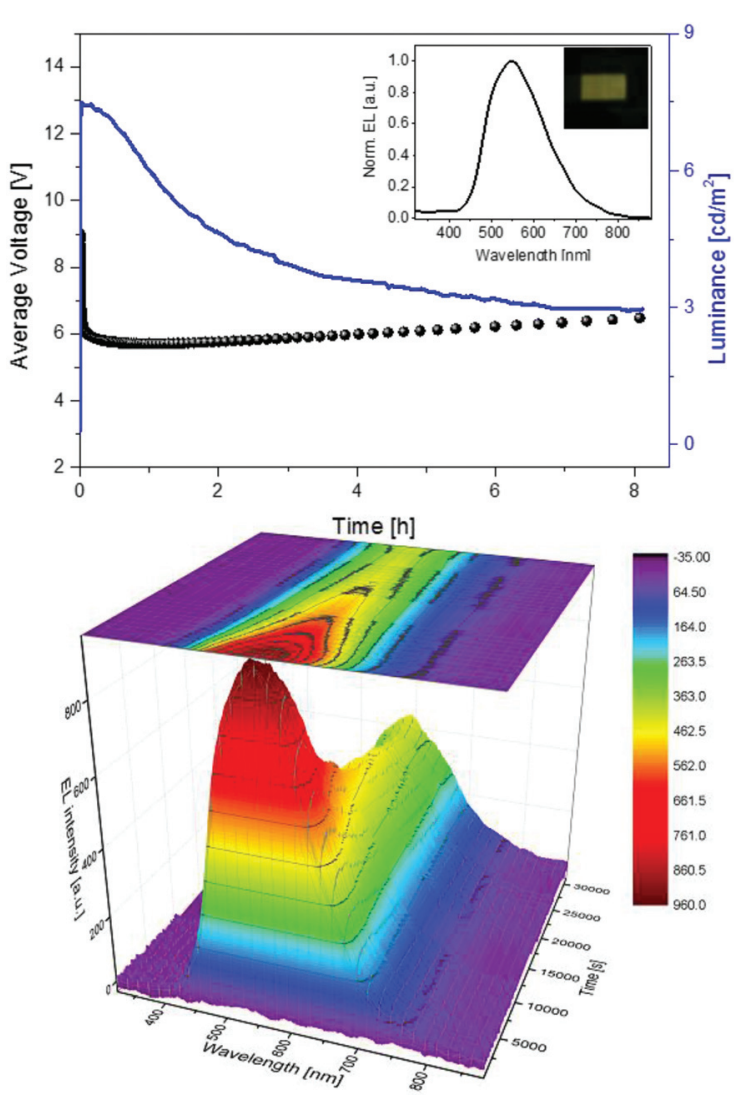

Fig. 5 (Top) Average voltage and luminance versus time of devices with 1 driven by a pulsed current using a block wave at a frequency of $1 \mathrm{kHz}$ with a duty cycle of $50 \%$ and an average current of $5 \mathrm{~mA}$. The inset shows the normalized EL and a picture of the device under working conditions. (Bottom) Changes of the EL spectrum over time.

Table 1 Figures-of-merit of devices with 1 driven at different pulsed currents using a block wave at a frequency of $1 \mathrm{kHz}$ with a duty cycle of $50 \%$

\begin{tabular}{lllll}
\hline Applied average current $[\mathrm{mA}]$ & 1 & 2.5 & 5 & 7.5 \\
\hline Luminance $\left[\mathrm{cd} \mathrm{m}^{-2}\right]$ & 2.85 & 5.59 & 7.5 & 13.9 \\
Efficacy $\left[\mathrm{cd} \mathrm{A}^{-1}\right]$ & 0.043 & 0.033 & 0.022 & 0.028 \\
Lifetime $\left(t_{1 / 2}\right)[\mathrm{h}]$ & 28.5 & 8.6 & 3.5 & 0.28
\end{tabular}

ing on the driving conditions - Fig. S6-8 $\dagger$ and Table 1. Much more striking are the changes of the EL spectrum under different applied currents. Similar to the LIV assays, the nature of the EL response is not altered during the lifespan of the device when applying currents superior to $5 \mathrm{~mA}$ - Fig. 5 and S8. $\dagger$ However, under low applied currents ( 1 and $2.5 \mathrm{~mA}$ ), the EL response relates to a similar structured band, whose maximum is initially located at $510 \mathrm{~nm}$ and rapidly changes to $\sim 550 \mathrm{~nm}(<1 \mathrm{~min})$ without any further change during the lifespan of the device - Fig. S6 and S7. $\uparrow$ This might be related to the thermal equilibration between vibrational states in the excited state due to an increase of the internal temperature of the device under driving conditions. ${ }^{12}$ 
In view of all of the aforementioned, the striking differences between PL and EL are not related to the driving conditions, device fabrication, device mechanism, and degradation of $\mathbf{1}$. Indeed, a shift of around 70-100 nm between PL and EL responses represents one of the largest reported in LECs to date. ${ }^{9,13-15,22-24}$ In general, the EL red-shifts around $20 \mathrm{~nm}$ compared to the PL due to the energy stabilization of the excited state under external electrical stimuli. ${ }^{9,10,15}$ In the few cases, in which a large shift has been reported, this has been rationalized in terms of (i) a change in the nature of the lowest emitting state due to the concentration effect of the films, ${ }^{54}$ and (ii) a reversible substitution of the ligands due to the weak coordination to the $\mathrm{Cu}(\mathrm{I}),{ }^{12}$ and (iii) a change in the distribution of excited states due to the polarization effects. ${ }^{55}$

As shown in Fig. 2, the blue photoluminescence spectra are similar for solution, crystalline powder, and thin films, discarding the first possible option. The latter two are also unlikely, since the yellow EL response holds under repetitive LIVs and lifetime tests at different driving conditions (Fig. 4, 5 and S6-8†) without apparent degradation as further corroborated by EIS assays (Fig. S5 $\dagger$ ). Thus, this counterintuitive finding might be related to an intrinsic behaviour of 1 concerning its emission mechanism.

To shed light on the scenario of electronic excited states involved in the photophysics of 1, DFT and TD-DFT calculations were performed. In detail, electron density redistribution, upon the lowest electronic transition, highlights the LC nature of the first singlet excited state $\left(S_{1}\right)$, deriving from a $\pi \rightarrow$ $\pi^{*}$ excitation centred on the 1-(pyridin-2-yl)imidazo[1,5- $\left.a\right]$ pyridine portion of the impy ligand - see electron-density difference maps and orbital composition in Table $\mathrm{S} 5 \dagger$ and Fig. 6. Similarly, the $\mathrm{T}_{1}$ state was calculated to be a ${ }^{3} \mathrm{LC}$ state, involving a $\pi-\pi^{*}$ transition localized on the 1 -(pyridin-2-yl)imidazo $[1,5-a]$ pyridine moiety (Table S5 $\dagger$ ). This fact is confirmed for the relaxed $\mathrm{T}_{1}$ by the spin-density distribution calculated at the optimized $\mathrm{T}_{1}$ geometry (Fig. 6). The two states $\left(\mathrm{S}_{1}\right.$ and $\left.\mathrm{T}_{1}\right)$ are nominally deriving from the same preponderant one-electron excitation, i.e. HOMO $\rightarrow$ LUMO (Table S6† and Fig. 6), where both the metal contribution and changes in their molecular structures are essentially negligible (Fig. 6).

Although a LC character is unusual for $\left[\mathrm{Cu}\left(\mathrm{N}^{\wedge} \mathrm{N}\right)\left(\mathrm{P}^{\wedge} \mathrm{P}\right)\right]^{+}$, in which the metal-charge transfer nature is classically observed,,$^{2,11,12,14,17,18,20-24}$ it is consistent with the structured shape of both PL and EL responses. Even if at the GS geometry, there are several triplet states $\left(\mathrm{T}_{1}-\mathrm{T}_{3}\right)$ lying between the optically populated $S_{1}$ and the ground state, at the structurally optimized $S_{1}$ and $T_{1}$ geometries, $S_{1}$ is separated from the ground state only by $\mathrm{T}_{1}$ (Fig. 6). Furthermore, TD-DFT calculations indicate that the next excited states are well separated (more than $0.3 \mathrm{eV}$ from $\mathrm{S}_{1}$ and $\mathrm{T}_{1}$ ). Thus, they might not impact the PL and EL emissions. This further supports the discarding of film concentration and external polarization effects - vide supra. Finally, the $\mathrm{S}_{1}-\mathrm{T}_{1}$ energy splitting $\left(\Delta E_{\mathrm{S}_{1}-\mathrm{T}_{1}}\right)$ of 1 is surprisingly large for a $\left[\mathrm{Cu}\left(\mathrm{N}^{\wedge} \mathrm{N}\right)\left(\mathrm{P}^{\wedge} \mathrm{P}\right)\right]^{+}$ system. ${ }^{2,11,12,14,17,18,20-24}$ In detail, the minimum of the potential energy surface of 1 in the $S_{1}$ excited state is located $0.44 \mathrm{eV}$
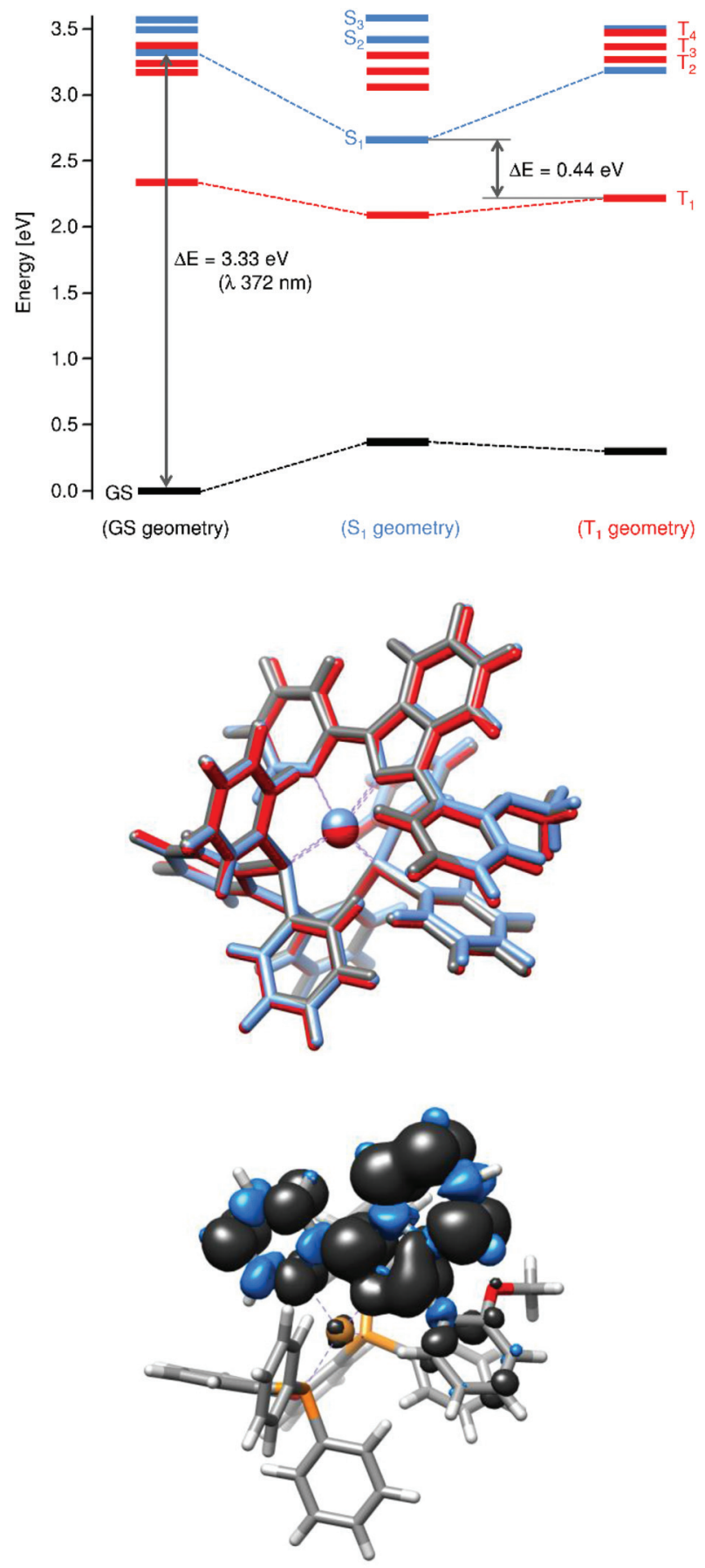

Fig. 6 Upper part - singlet and triplet energy level diagram for 1, calculated at optimized ground-state (GS), singlet excited state $\left(\mathrm{S}_{1}\right)$ and lowest-lying triplet state $\left(\mathrm{T}_{1}\right)$ geometries (black: ground state; blue: excited singlet states; red: triplet states). Central part - overlap of DFToptimized structures of 1 in the GS (gray), $S_{1}$ (blue) and $T_{1}$ (red) electronic states. Bottom part - contour plot of the spin density of 1 in the $\mathrm{T}_{1}$ geometry (isovalue $=0.0004$ ) .

above the energy of the system at the $\mathrm{T}_{1}$ optimized geometry, leading to a $\Delta E_{\mathrm{S}_{1}-\mathrm{T}_{1}}>3000 \mathrm{~cm}^{-1}$. This points to a lack of TADF that can be easily explained by the LC nature of the excited state that provides a large exchange integral between both 
excited states, as suggested by the large $\Delta E_{\mathrm{S}_{1}-\mathrm{T}_{1}} \cdot{ }^{7,8,17,18,21,56} \mathrm{~A}$ prime factor for a TADF process is the quasi-energy degeneration between $\mathrm{S}_{1}$ and $\mathrm{T}_{1}$, i.e., $\Delta E_{\mathrm{S}_{1}-\mathrm{T}_{1}}=100-800 \mathrm{~cm}^{-1}$, allowing the thermal population of the singlet from the triplet state. ${ }^{7,8,17,18,21}$ Hence, the repopulation of $S_{1}$ might be significantly hampered for $\mathbf{1}$ due to the large energetic barrier.

To further support this notion, the PL features of $\mathbf{1}$ were investigated at $77 \mathrm{~K}$ in both crystalline powder and ACN solution. Here, it is expected that a complex with a TADF radiative mechanism shows a red-shifted PL upon cooling. However, Fig. 7 displays that the high-energy structured emission band is blue-shifted (5 nm) upon freezing without shifting the whole spectrum. This behavior is typical of a single excited state mechanism. This is also in line with the short excited state lifetime. Much more relevant is the appearance of a new structured band at $\sim 550 \mathrm{~nm}$ with a typical vibrational progression of $\mathrm{C}=\mathrm{C}$ and $\mathrm{C}=\mathrm{N}$ stretching $\left(\sim 1450 \mathrm{~cm}^{-1}\right)$ that is further confirmed to be a triplet emission via delayed mode measurements - see the Experimental section. The latter lies at similar energies to that noted for the EL response, suggesting that 1 shows EL and PL responses attributed to $T_{1}$ and $S_{1}$ excited states, respectively. This is not surprising, since
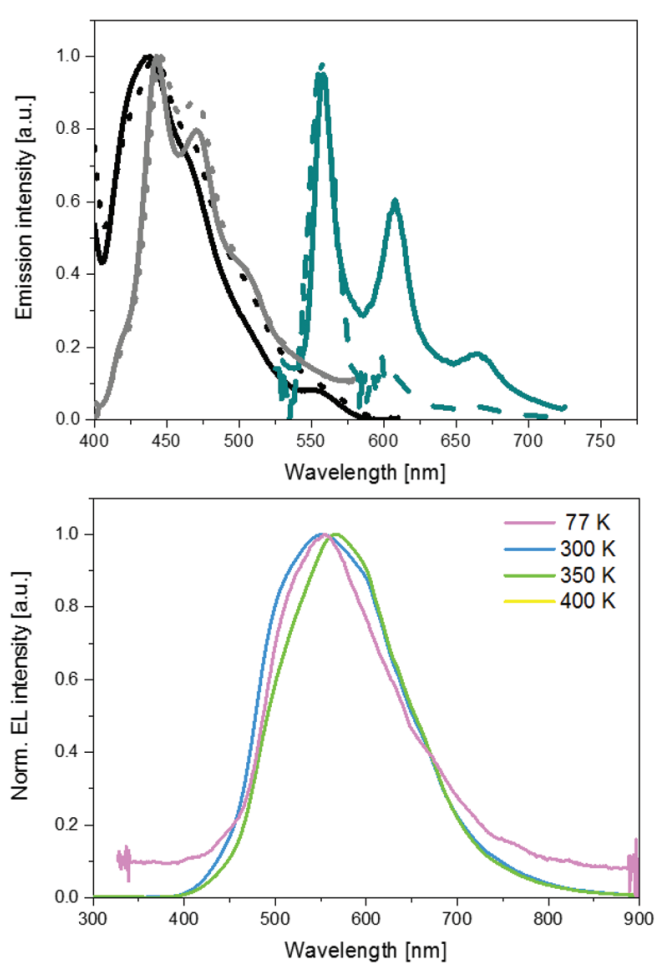

Fig. 7 Upper part - emission spectra of 1 measured in crystalline powder at rt (black dotted line) and $77 \mathrm{~K}$ (black solid line) by using a fluorescence mode. Emission spectra of 1 measured in crystalline powder (green dashed line) and solution (green solid line) at $77 \mathrm{~K}$ by using a phosphorescence mode. For comparison purposes, the emission of the impy ligand in crystalline powder at rt (grey dotted line) and $77 \mathrm{~K}$ (grey solid line) by using a fluorescence mode. No signal was detected by using a phosphorescence mode. Bottom part - EL spectra of devices with 1 driven at constant voltage of $10 \mathrm{~V}$ at $77,300,350$, and $400 \mathrm{~K}$. in the devices the electron-hole spin statistic recombination is $75 \%$ for triplets and $25 \%$ for singlets. As such, the weak yellow phosphorescence is the most likely mechanism for the EL, explaining the moderate device performance in terms of luminance and efficacy. This holds even when thinner devices were tested as summarized in Table S7. $\dagger$

In light of these findings, we performed a final attempt to activate the TADF mechanism under device operation conditions by heating the device from 77 to $400 \mathrm{~K}$ (Fig. 7). Compared to the EL spectrum at $300 \mathrm{~K}$, the EL spectrum at a lower temperature shows the same band shape, but is slightly blueshifted, while the increase of the temperature up to $400 \mathrm{~K}$ did not cause any profound change in the EL response. Therefore, the activation of the fluorescence and/or TADF mechanism in the device is not possible.

\section{Conclusions}

In summary, this work provides the synthesis and a comprehensive structural, photophysical, electrochemical, and theoretical characterization of a new member of the family of $\left[\mathrm{Cu}\left(\mathrm{N}^{\wedge} \mathrm{N}\right)\left(\mathrm{P}^{\wedge} \mathrm{P}\right)\right]^{+}$complexes. Although this compound shows blue emission and reversible redox features that encourage its application in LECs, the latter turn out to be yellow emitting devices. This is attributed to the formation of $T_{1}$ upon electron-hole recombination. The $\mathrm{T}_{1}$ cannot be transformed via the TADF process back to $\mathrm{S}_{1}$, even if the devices are tested at high temperatures. This explains the large shift observed between the PL and EL responses, as well as the moderate device performance in terms of luminance and efficacy. The latter could be enhanced by using charge injection and transport layers like in OLEDs. This unique finding in $\left[\mathrm{Cu}\left(\mathrm{N}^{\wedge} \mathrm{N}\right)\right.$ $\left.\left(\mathrm{P}^{\wedge} \mathrm{P}\right)\right]^{+}$is attributed to the LC nature of the emitting excited states, suppressing the TADF feature as recently reported by several groups. ${ }^{7,8,17,18,21}$ Overall, this work is a clear insight for the design of new copper(I) complexes towards the preparation of blue LECs, which are a still unexplored field.

\section{Experimental section}

\section{Materials and methods}

All chemicals were purchased from chemical suppliers and used without further purification. All analytical reagent grade solvents were purified by distillation. PEDOT:PSS (Clevios PAl4083) was purchased from Heraeus. Microwave-assisted reactions were carried out by using a Biotage Initiator EXP synthesizer. Reactions were conducted in Biotage microwave vials which were loaded using dried solvents. NMR spectra were recorded on a Bruker Avance 200 spectrometer $\left({ }^{1} \mathrm{H}\right.$ NMR operating frequency: $200 \mathrm{MHz}$ ) with chemical shifts referenced to residual protons of the solvent. The following abbreviations are used: s, singlet; d, doublet; t, triplet; m, multiplet. Highresolution mass spectra were recorded on an LTQ Orbitrap Hybrid Mass Spectrometer. 


\section{Synthesis of the ancillary impy ligand}

3-(2-Methoxyphenyl)-1-(pyridine-2-yl)imidazo[1,5-a]pyridine was obtained by applying a microwave-assisted organic synthesis, starting from 2,2'-dipyridil ketone and 2-methoxybenzaldehyde. 2,2'-Dipyridil ketone (0.308 g, $1.672 \mathrm{mmol}), 2$-methoxybenzaldehyde $(0.462 \mathrm{~g}, 3.397 \mathrm{mmol})$, ammonium acetate $(0.675 \mathrm{~g}$, $8.752 \mathrm{mmol}$ ) and $15 \mathrm{ml}$ of acetic acid were placed in a sealed $25 \mathrm{ml}$ microwave reactor flask. The mixture was stirred at room temperature until dissolution, then the reaction mixture was stirred at $180^{\circ} \mathrm{C}$ for $1 \mathrm{~h}$ and finally cooled to room temperature. The reaction was monitored by TLC (dichloromethane/methanol $96: 4)$. The resulting solution was distilled under vacuum. A saturated solution of sodium carbonate in water was then added cautiously to the residue mixture. The product was extracted in dichloromethane $(3 \times 20 \mathrm{ml})$. The organic solutions were collected together and washed subsequently with $20 \mathrm{ml}$ of basic solution $\left(\mathrm{Na}_{2} \mathrm{CO}_{3} 5 \mathrm{vol} \%\right.$ solution) and $20 \mathrm{ml}$ of water. The organic solvent was then dried and evaporated. The resulting yellow solid was purified by washing with a $1: 1$ mixture of diethyl ether and petroleum ether, in which only the reagents are soluble. The washing process was monitored via TLC and afforded the pure 3-(2-methoxyphenyl)-1-(pyridine-2-yl)imidazo $[1,5-a]$ pyridine $(0.368 \mathrm{~g}, 73 \%) . \delta \mathrm{H}\left(200 \mathrm{MHz}\right.$; acetone- $\left.\mathrm{d}_{6}\right) 8.72$ (1H, m), 8.62 (1H, m), $8.21(1 \mathrm{H}, \mathrm{d}, \mathrm{J} 1.2 \mathrm{~Hz}), 7.79(1 \mathrm{H}, \mathrm{m}), 7.75$ $(1 \mathrm{H}, \mathrm{m}), 7.63(1 \mathrm{H}, \mathrm{m}), 7.55(1 \mathrm{H}, \mathrm{m}), 7.21(1 \mathrm{H}, \mathrm{m}), 7.15(1 \mathrm{H}, \mathrm{m})$, $7.11(1 \mathrm{H}, \mathrm{m}), 7.03(1 \mathrm{H}, \mathrm{m}), 6.75(1 \mathrm{H}, \mathrm{m}), 3.86(3 \mathrm{H}, \mathrm{s}) . \delta \mathrm{C}$ (50 MHz, acetone- $\mathrm{d}_{6}$ ) 158.4, 156.5, 149.8, 137.1, 136.9, 133.3, $131.8,130.7,125.4,125.4,124.7,121.8,121.7,121.0,120.5$, 120.0, 113.6, 112.3, 55.9. Mass: $\mathrm{ESI}^{+} m / z 302.1330\left(\mathrm{M}+\mathrm{H}^{+}\right)$; ESI-MS/MS $m / z \quad 302.1330\left(\mathrm{M}+\mathrm{H}^{+}\right), m / z 287.1080\left(\mathrm{M}+\mathrm{H}^{+}-\right.$ $\left.\mathrm{CH}_{3}\right)$.

\section{Synthesis of $[\mathrm{Cu}(\mathrm{impy})(\mathrm{POP})]\left[\mathrm{PF}_{6}\right](1)$}

In a $50 \mathrm{ml}$ three-necked round-bottom flask $\left[\mathrm{Cu}\left(\mathrm{CH}_{3} \mathrm{CN}\right)_{4}\right] \mathrm{PF}_{6}$ $(0.124 \mathrm{~g}, 0.333 \mathrm{mmol})$ and POP $(0.186 \mathrm{~g}, 0.345 \mathrm{mmol})$ were mixed at room temperature under a nitrogen atmosphere. The solid reagents were then dissolved in $15 \mathrm{~mL}$ of freshly distilled dichloromethane and the mixture was stirred at room temperature for 30 minutes. Then $15 \mathrm{ml}$ of a deaerated dichloromethane solution of impy (0.105 g, $0.349 \mathrm{mmol})$ was added into the reaction flask, generating an instantaneous change of the solution color that became yellow-orange. The solution was stirred for an additional 30 minutes under a nitrogen atmosphere at room temperature. The nitrogen flux was then removed and the solvent evaporated, providing a yellow solid powder. The solid was washed with diethyl ether to separate the product from the unreacted ligand. The purification was monitored via TLC and afforded complex $1(0.297 \mathrm{~g}, 85 \%) . \delta \mathrm{H}$ (200 MHz; acetone-d $\left.{ }_{6}\right) 8.38(1 \mathrm{H}, \mathrm{d}), 8.31(1 \mathrm{H}, \mathrm{s}), 7.97(1 \mathrm{H}, \mathrm{s})$, $7.95(1 \mathrm{H}, \mathrm{d}), 7.82(1 \mathrm{H}, \mathrm{s}), 7.76(1 \mathrm{H}, \mathrm{d}), 7.72(1 \mathrm{H}, \mathrm{m}), 7.41(1 \mathrm{H}$, d), $7.36(1 \mathrm{H}, \mathrm{d}), 7.33(1 \mathrm{H}, \mathrm{s}), 7.29(1 \mathrm{H}, \mathrm{s}), 7.17(4 \mathrm{H}, \mathrm{d}), 7.02$ $(1 \mathrm{H}, \mathrm{d}), 6.95(1 \mathrm{H}, \mathrm{d}), 6.92(1 \mathrm{H}, \mathrm{m}), 6.86(1 \mathrm{H}, \mathrm{d}), 6.83(1 \mathrm{H}, \mathrm{d})$, $6.78(1 \mathrm{H}, \mathrm{s}), 3.74(3 \mathrm{H}, \mathrm{s}) . \delta \mathrm{C}\left(50 \mathrm{MHz}\right.$, acetone- $\left.\mathrm{d}_{6}\right) 157.7,150.3$, $148.9,138.2,136.9,136.2,134.5,134.3,134.2,134.0,133.9$, $132.8,132.7,132.6,132.4,132.4,132.3,132.3,132.1,132.0$,
$132.0,130.3,130.3,129.9,129.8,129.7,129.7,129.6,129.6$, $129.3,129.2$, 129.1, 129.0, 128.7, 128.7, 128.7, 128.6, 128.6, $128.5,128.5,128.5,128.4,128.4,127.4,124.8,124.6,121.8$, 121.2, 120.2, 119.6, 117.8, 116.6, 114.4, 112.0, 55.1. Mass: $\mathrm{ESI}^{+}$ $m / z=902.2196\left(\mathbf{M}^{+}\right)$; ESI-MS/MS m/z $601.0938\left(\mathbf{M}^{+}-\right.$impy).

\section{Crystallographic characterization}

Single-crystal diffraction data were collected using an Oxford Xcalibur CCD area detector diffractometer. Structure solution was performed using SIR2011 ${ }^{32}$ and refinement with fullmatrix least-squares using SHELXL-2013. ${ }^{33}$ Mercury ${ }^{34}$ was used for crystal structure drawing. A suitable crystal was grown by slow vapor diffusion of diethylether into a dichloromethane solution of 1. Despite all crystallization attempts, the crystal grows in aggregates of very thin laminae. To obtain suitable XRD data a very large (to have sufficient diffraction volume) but very thin (to avoid twinning) lamina was used. The crystal, despite its weakly diffracting nature, resulted in being suitable for structure solution and refinement. The structure resulted in being ordered, also in the $\mathrm{PF}_{6}{ }^{-}$anion, that was often found to be disordered in similar structures. ${ }^{35-37}$ Relevant XRD data are reported in the ESI. $\uparrow$ The crystal structure was deposited into CCDC with reference number 1452806.

\section{Photophysical and electrochemical characterization}

Steady-state absorption spectra were recorded with a Perkin Elmer Lambda 35. Steady-state emission spectra were recorded with a Fluoromax-P-spectrometer from HORIBA Jobin Yvon IBH by using fluorescence and phosphorescence modes (measurement after $10 \mathrm{~ns}$ ). The crystalline powder and spincoated films were prepared on quartz slides and measured in air, solution measurements were performed in degassed acetonitrile (ACN). Low temperature experiments were carried out by freezing the samples sandwiched in between two sealed quartz slides in liquid nitrogen. Fluorescence lifetime and quantum yield measurements were performed using a Fluorolog-3 spectrofluorimeter (HORIBA Jobin Yvon IBH) equipped with a Quanta- $\varphi$ integrating sphere. Luminescence lifetimes were determined by time-correlated single-photon counting. The excitation was adjusted to the absorption maximum using nano-LEDs with a pulse width $<100$ ps. Data were collected into 2048 channels to 10000 counts in the peak channel. Emission decay data were analyzed by using the software DAS6 (TCSPC Decay Analysis Software). Fluorescence lifetimes were measured at the emission maximum at room temperature in degassed solutions in a 1 to $1 \mathrm{~cm}$ quartz cuvette and the obtained values were fitted by means of a mono-exponential function. Cyclic voltammetry was performed with a Methrom $\mu$ AutolabIII/FRA3, with a glassy carbon electrode as the working electrode, a silver wire as the pseudo-reference electrode, and a platinum wire as the counter electrode. All spectra were recorded in ACN with tetrabutylammonium hexafluorophosphate $(0.1 \mathrm{M})$ electrolyte and corrected $v s . \mathrm{Fc}_{\mathrm{Fc}}{ }^{+}(0.338 \mathrm{~V})$. 


\section{Theoretical characterization}

All the calculations were performed by the Gaussian 09 (G09) program package, ${ }^{38}$ employing density functional theory (DFT) and the time dependent (TD)-DFT methods, ${ }^{39,40}$ the Becke three-parameter hybrid functional, ${ }^{41}$ and the Lee-Yang-Parr gradient-corrected correlation functional (B3LYP). ${ }^{42}$ The solvent effect was included by using the conductor-like polarizable continuum model (CPCM) with ACN as the solvent. ${ }^{43,44}$ The LanL2DZ basis set ${ }^{45}$ and effective core potential were used for the $\mathrm{Cu}$ atom and the $6-31 \mathrm{G}^{* *}$ basis set ${ }^{46}$ was used for all the other atoms. Geometry optimizations of the ground state (GS) and the lowest-lying triplet state (T1) were carried out without any symmetry constraints. The nature of GS and T1 optimized structures was verified by using harmonic vibrational frequency calculations. No imaginary frequencies were found, thus indicating we had located the minima on the potential-energy surfaces. The UV/Vis electronic absorption spectrum of 1 in the GS was simulated computing a total of 128 singlet excited states by using TD-DFT. The electronic distribution and the localization of the singlet excited states were visualized by using electron-density difference maps (EDDMs). GaussSum 2.2.5 ${ }^{47}$ was used to simulate the theoretical UV/Vis spectra and for extraction of EDDMs. ${ }^{48,49}$ Moreover, 8 singlet and 8 triplet excited states were calculated for each optimized geometry (GS, S1, T1). Molecular-graphic images were produced by using the UCSF Chimera package from the Resource for Biocomputing, Visualization, and Informatics at the University of California, San Francisco (supported by NIGMS P41GM103311). ${ }^{50}$

\section{Device fabrication and analysis}

Double layer LECs were fabricated as follows. ITO coated glass plates were patterned by conventional photolithography (Naranjo Substrates). The substrates were cleaned by using sequential ultrasonic baths, namely in water-soap, water, ethanol, and propan-2-ol solvents. After drying, the substrates were placed in a UV-ozone cleaner (Jetlight 42-220) for $8 \mathrm{~min}$. An $90 \mathrm{~nm}$ layer of PEDOT:PSS was doctor-bladed onto the ITOglass substrate to increase the device preparation yield (400 $\mu \mathrm{m}$ blade to substrate distance and a coating speed of $10 \mathrm{~mm} \mathrm{~s}^{-1}$ ). The luminescent layer was entirely prepared with 1. The thick $(90 \mathrm{~nm})$ and thin $(45 \mathrm{~nm})$ active layers were prepared by means of spin coating (800 and $1000 \mathrm{rpm}$ spinning velocity, respectively) from acetonitrile solution $(20 \mathrm{mg} \mathrm{mL}$ and $10 \mathrm{mg} \mathrm{mL}^{-1}$, respectively). These conditions resulted in homogeneous thin films with a roughness less than 5\%, having no apparent optical defects. The latter was determined using the profilometer DektakxT from Bruker. Once the active layer was deposited, the samples were transferred into an inert atmosphere glovebox $\left(<0.1 \mathrm{ppm} \mathrm{O}_{2}\right.$ and $\mathrm{H}_{2} \mathrm{O}$, Innovative Technology). The aluminum cathode electrode (90 nm) was thermally evaporated using a shadow mask under high vacuum $\left(<1 \times 10^{-6}\right.$ mbar $)$ with an Angstrom Covap evaporator integrated into the inert atmosphere glovebox. Time dependence of luminance, voltage, and current was measured by applying constant and/or pulsed voltage and current by monitoring the desired parameters simultaneously by using an Avantes spectrophotometer (Avaspec-ULS2048L-USB2) in conjunction with a calibrated integrated sphere Avasphere 30-Irrad and Botest OLT OLED Lifetime-Test System. Electroluminescence spectra were recorded using the above mentioned spectrophotometer. Luminescence-current-voltage-sweeps (LIVs) were measured with the same setup and were performed by ramping up the voltage from $-18 \mathrm{~V}$ to $12 \mathrm{~V}$ at a step of $0.25 \mathrm{~V}$ and $0.5 \mathrm{~V}$ for the negative and positive range, respectively. Electrochemical impedance spectroscopic assays (EIS) were carried out with a potentiostat/galvanostat (Metrohm $\mu$ AutolabIII) equipped with a frequency response analyzer module (FRA). Measurements were performed at an applied voltage ranging from 0 to $6.5 \mathrm{~V}$. The AC signal amplitude was set to $10 \mathrm{mV}$, modulated in a frequency range from 10 to $1 \mathrm{MHz}$. The Nova 1.11 software was used to obtain the parameters from the equivalent circuit. With this data at hand, the resistance of the intrinsic non-doped region $\left(R_{\text {pin }}\right)$ was directly obtained.

\section{Acknowledgements}

RDC and MDW acknowledge funding by the 'Fonds der Chemischen Industrie' (FCI) in the Liebig grant framework and the Cluster of Excellence 'Engineering of Advanced Materials' (EAM), CB gratefully acknowledges financial support by the DSSCX project (PRIN 2010-2011, 20104XET32) from Ministero dell'Istruzione, dell'Università e della Ricerca and Università di Torino (Ricerca Locale ex-60\%, Bando 2015). The authors declare no competing financial interests.

\section{Notes and references}

1 D. Volz, M. Wallesch, C. Fléchon, M. Danz, A. Verma, J. M. Navarro, M. Zink, S. Bräse and T. Baumann, Green Chem., 2015, 17, 1988-2011.

2 R. Czerwieniec and H. Yersin, Inorg. Chem., 2015, 54, 43224327.

3 Y. Tao, K. Yuan, T. Chen, P. Xu, H. Li, R. Chen, C. Zheng, L. Zhang and W. Huang, Adv. Mater., 2014, 26, 7931-7958.

4 M. Hashimoto, S. Igawa, M. Yashima, I. Kawata, M. Hoshino and M. Osawa, J. Am. Chem. Soc., 2011, 133, 10348-10351.

5 X.-L. Chen, C.-S. Lin, X.-Y. Wu, R. Yu, T. Teng, Q.-K. Zhang, Q. Zhang, W.-B. Yang and C.-Z. Lu, J. Mater. Chem. C, 2015, 3, 1187-1195.

6 F. Dumur, Org. Electron., 2015, 21, 27-39.

7 E. Cariati, E. Lucenti, C. Botta, U. Giovanella, D. Marinotto and S. Righetto, Coord. Chem. Rev., 2015, 306, 566-614.

8 K. Tsuge, Y. Chishina, H. Hashiguchi, Y. Sasaki, M. Kato, S. Ishizaka and N. Kitamura, Coord. Chem. Rev., 2016, 306, 636-651.

9 R. D. Costa, E. Ortí, H. J. Bolink, F. Monti, G. Accorsi and N. Armaroli, Angew. Chem., Int. Ed., 2012, 51, 8178-8211. 
10 T. Hu, L. He, L. Duan and Y. Qiu, J. Mater. Chem., 2012, 22, 4206-4215.

11 C. Bizzarri, C. Strabler, J. Prock, B. Trettenbrein, M. Ruggenthaler, C.-H. Yang, F. Polo, A. Iordache, P. Brüggeller and L. De Cola, Inorg. Chem., 2014, 53, 1094410951.

12 D. Asil, J. A. Foster, A. Patra, X. de Hatten, J. del Barrio, O. A. Scherman, J. R. Nitschke and R. H. Friend, Angew. Chem., Int. Ed., 2014, 53, 8388-8391.

13 J.-J. Cid, J. Mohanraj, M. Mohankumar, M. Holler, F. Monti, G. Accorsi, L. Karmazin-Brelot, I. Nierengarten, J. M. Malicka, M. Cocchi, B. Delavaux-Nicot, N. Armaroli and J.-F. Nierengarten, Polyhedron, 2014, 82, 158-172.

14 S. Keller, E. C. Constable, C. E. Housecroft, M. Neuburger, A. Prescimone, G. Longo, A. Pertegás, M. Sessolo and H. J. Bolink, Dalton Trans., 2014, 43, 16593-16596.

15 S. B. Meier, D. Tordera, A. Pertegás, C. Roldán-Carmona, E. Ortí and H. J. Bolink, Mater. Today, 2014, 17, 217223.

16 S. Keller, A. Pertegás, G. Longo, L. Martínez, J. Cerdá, J. M. Junquera-Hernández, A. Prescimone, E. C. Constable, C. E. Housecroft, E. Ortí and H. J. Bolink, J. Mater. Chem. C, 2016, 4, 3857-3871.

17 C. L. Linfoot, M. J. Leitl, P. Richardson, A. F. Rausch, O. Chepelin, F. J. White, H. Yersin and N. Robertson, Inorg. Chem., 2014, 53, 10854-10861.

18 M. J. Leitl, V. A. Krylova, P. I. Djurovich, M. E. Thompson and H. Yersin, J. Am. Chem. Soc., 2014, 136, 16032-16038.

19 Y. Tao, K. Yuan, T. Chen, P. Xu, H. Li, R. Chen, C. Zheng, L. Zhang and W. Huang, Adv. Mater., 2014, 26, 7931-7958.

20 A. Kaeser, M. Mohankumar, J. Mohanraj, F. Monti, M. Holler, J.-J. Cid, O. Moudam, I. Nierengarten, L. Karmazin-Brelot, C. Duhayon, B. Delavaux-Nicot, N. Armaroli and J.-F. Nierengarten, Inorg. Chem., 2013, 52, 12140-12151.

21 A. Kaeser, O. Moudam, G. Accorsi, I. Séguy, J. Navarro, A. Belbakra, C. Duhayon, N. Armaroli, B. Delavaux-Nicot and J.-F. Nierengarten, Eur. J. Inorg. Chem., 2014, 8, 13451355.

22 Q. Zhang, Q. Zhou, Y. Cheng, L. Wang, D. Ma, X. Jing and F. Wang, Adv. Funct. Mater., 2006, 16, 1203-1208.

23 N. Armaroli, G. Accorsi, M. Holler, O. Moudam, J.-F. Nierengarten, Z. Zhou, R. T. Wegh and R. Welter, Adv. Mater., 2006, 18, 1313-1316.

24 R. D. Costa, D. Tordera, E. Ortí, H. J. Bolink, J. Schönle, S. Graber, C. E. Housecroft, E. C. Constable and J. A. Zampese, J. Mater. Chem., 2011, 21, 16108-16118.

25 C. D. Sunesh, G. Mathai and Y. Choe, Org. Electron., 2014, 15, 667-674.

26 F. Kessler, R. D. Costa, D. Di Censo, R. Scopelliti, E. Ortí, H. J. Bolink, S. Meier, W. Sarfert, M. Grätzel, M. K. Nazeeruddin and E. Baranoff, Dalton Trans., 2012, 41, 180-191.

27 J. M. Fernández-Hernández, S. Ladouceur, Y. Shen, A. Iordache, X. Wang, L. Donato, S. Gallagher-Duval, M. de
Anda Villa, J. D. Slinker, L. De Cola and E. ZysmanColman, J. Mater. Chem. C, 2013, 1, 7440-7452.

28 Photochemistry and Photophysics of Coordination Compounds I, ed. V. Balzani and S. Campagna, Springer, Berlin, Heidelberg, 2007, vol. 280.

29 L. Salassa, C. Garino, A. Albertino, G. Volpi, C. Nervi, R. Gobetto and K. I. Hardcastle, Organometallics, 2008, 27, 1427-1435.

30 C. Garino, T. Ruiu, L. Salassa, A. Albertino, G. Volpi, C. Nervi, R. Gobetto and K. I. Hardcastle, Eur. J. Inorg. Chem., 2008, 3587-3591.

31 J. Wang, L. Dyers, R. Mason, P. Amoyaw and X. R. Bu, J. Org. Chem., 2005, 70, 2353-2356.

32 M. C. Burla, R. Caliandro, M. Camalli, B. Carrozzini, G. L. Cascarano, C. Giacovazzo, M. Mallamo, A. Mazzone, G. Polidori and R. Spagna, J. Appl. Crystallogr., 2012, 45, 357-361.

33 G. M. Sheldrick, Acta Crystallogr., Sect. D: Biol. Crystallogr., 2010, 66, 479-485.

34 C. F. Macrae, I. J. Bruno, J. A. Chisholm, P. R. Edgington, P. McCabe, E. Pidcock, L. Rodriguez-Monge, R. Taylor, J. van de Streek and P. A. Wood, J. Appl. Crystallogr., 2008, 41, 466-470.

35 R. Gobetto, C. Nervi, B. Romanin, L. Salassa, M. Milanesio and G. Croce, Organometallics, 2003, 22, 4012-4019.

36 C. Garino, R. Gobetto, C. Nervi, L. Salassa, G. Croce, M. Milanesio, E. Rosenberg and J. B. A. Ross, Eur. J. Inorg. Chem., 2005, 3, 606-614.

37 R. Gobetto, G. Caputo, C. Garino, S. Ghiani, C. Nervi, L. Salassa, E. Rosenberg, J. B. A. Ross, G. Viscardi, G. Martra, I. Miletto and M. Milanesio, Eur. J. Inorg. Chem., 2006, 14, 2839-2849.

38 M. J. Frisch, G. W. Trucks, H. B. Schlegel, G. E. Scuseria, M. A. Robb, J. R. Cheeseman, G. Scalmani, V. Barone, B. Mennucci, G. A. Petersson, H. Nakatsuji, M. Caricato, X. Li, H. P. Hratchian, A. F. Izmaylov, J. Bloino, G. Zheng, J. L. Sonnenberg, M. Hada, M. Ehara, K. Toyota, R. Fukuda, J. Hasegawa, M. Ishida, T. Nakajima, Y. Honda, O. Kitao, H. Nakai, T. Vreven, J. A. Montgomery, Jr., J. E. Peralta, F. Ogliaro, M. Bearpark, J. J. Heyd, E. Brothers, K. N. Kudin, V. N. Staroverov, R. Kobayashi, J. Normand, K. Raghavachari, A. Rendell, J. C. Burant, S. S. Iyengar, J. Tomasi, M. Cossi, N. Rega, J. M. Millam, M. Klene, J. E. Knox, J. B. Cross, V. Bakken, C. Adamo, J. Jaramillo, R. Gomperts, R. E. Stratmann, O. Yazyev, A. J. Austin, R. Cammi, C. Pomelli, J. W. Ochterski, R. L. Martin, K. Morokuma, V. G. Zakrzewski, G. A. Voth, P. Salvador, J. J. Dannenberg, S. Dapprich, A. D. Daniels, Ö. Farkas, J. B. Foresman, J. V. Ortiz, J. Cioslowski and D. J. Fox, Gaussian 09, Revis. E.01, Gaussian, Inc., Wallingford CT, 2009.

39 M. E. Casida, C. Jamorski, K. C. Casida and D. R. Salahub, J. Chem. Phys., 1998, 108, 4439.

40 R. E. Stratmann, G. E. Scuseria and M. J. Frisch, J. Chem. Phys., 1998, 109, 8218. 
41 A. D. Becke, J. Chem. Phys., 1993, 98, 5648-5652.

42 C. Lee, W. Yang and R. G. Parr, Phys. Rev. B: Condens. Matter, 1988, 37, 785-789.

43 M. Cossi, G. Scalmani, N. Rega and V. Barone, J. Chem. Phys., 2002, 117, 43-54.

44 S. Miertuš, E. Scrocco and J. Tomasi, Chem. Phys., 1981, 55, 117-129.

45 P. J. Hay and W. R. Wadt, J. Chem. Phys., 1985, 82, 270283.

46 A. D. McLean and G. S. Chandler, J. Chem. Phys., 1988, 72, 5639-5648.

47 N. M. O’Boyle, A. L. Tenderholt and K. M. Langner, J. Comput. Chem., 2008, 29, 839-845.

48 W. R. Browne, N. M. O’Boyle, J. J. McGarvey and J. G. Vos, Chem. Soc. Rev., 2005, 34, 641-663.

49 M. Head-Gordon, A. M. Grana, D. Maurice and C. A. White, J. Phys. Chem., 1995, 99, 14261-14270.
50 E. F. Pettersen, T. D. Goddard, C. C. Huang, G. S. Couch, D. M. Greenblatt, E. C. Meng and T. E. Ferrin, J. Comput. Chem., 2004, 25, 1605-1612.

51 G. Volpi, C. Garino, E. Conterosito, C. Barolo, R. Gobetto and G. Viscardi, Dyes Pigm., 2016, 128, 96-100.

52 S. B. Meier, D. Hartmann, A. Winnacker and W. Sarfert, J. Appl. Phys., 2014, 116, 104504-104508.

53 A. Munar, A. Sandström, S. Tang and L. Edman, Adv. Funct. Mater., 2012, 22, 1511-1517.

54 H. J. Bolink, L. Cappelli, S. Cheylan, E. Coronado, R. D. Costa, N. Lardiés, M. K. Nazeeruddin and E. Ortí, J. Mater. Chem., 2007, 17, 5032-5041.

55 Y.-M. Wang, F. Teng, Y.-B. Hou, Z. Xu, Y.-S. Wang and W.-F. Fu, Appl. Phys. Lett., 2005, 87, 233512-233515.

56 A. M. Blanco-Rodríguez, H. Kvapilova, J. Sykora, M. Towrie, C. Nervi, G. Volpi, S. Zalis and A. Vlcek, J. Am. Chem. Soc., 2014, 136, 5963-5973. 